\title{
The Development of Prospective Middle Level Teachers' Mathematical Knowledge in a Multi-site Educational Setting
}

\author{
David Slavit ${ }^{1^{*}}$, Allison Therese deVincenzi ${ }^{1}$ \\ ${ }^{7}$ Washington State University Vancouver, USA \\ * CORRESPONDENCE: $\square$ dslavit@wsu.edu
}

\begin{abstract}
This case study explores the degree to which mathematical knowledge for teaching can be developed by prospective teachers in a multi-site teacher education context. The majority of the article focuses on a description of the target middle level mathematics endorsement program, including distance-based instructional norms, community building efforts, and tasks and activities intended to support the generation of mathematical knowledge for teaching. All preservice teachers enrolled in the program were invited to participate in the study. Means on Likert-scale survey items were calculated at three points in time over one year to determine changes. Openended survey items and focus group interviews were analyzed qualitatively to supplement the quantitative findings. These data support the result that middle level preservice teachers' mathematical knowledge for teaching can be positively impacted by a middle level mathematics teacher education program. Two broader implications are provided: 1) teacher education experiences can have positive impact on prospective teachers' development, and 2) this development is possible in a multi-site teacher education setting. Possible implications on international teacher education efforts are provided.
\end{abstract}

Keywords: teacher education, middle level mathematics, multi-site education, distance education, mathematical knowledge for teaching

\section{INTRODUCTION}

We explore the development of specific mathematical understandings of prospective teachers (PSTs) as they progress through a multi-site teacher education program focused on mathematics. Our research question is: To what degree does a multi-site middle-level mathematics endorsement program support prospective teachers' development of mathematical understandings? The specific aspects of mathematical understanding we address include overall mathematical content knowledge, problem solving, justification, connections between mathematical concepts, and fluency with multiple representations.

Our multi-site teacher education program resides entirely in the northwestern United States. As technological innovations and shifts to video-based or online learning continue, teacher educators should consider more the affordances and limitations of multi-site teacher education programs. Multi-site studies of teacher education are not uncommon (Abell \& colleagues, 2007; Zeichner \& Conklin, 2008). For example, Lewin and Stuart (2003) provided an international synthesis of research on teacher education in Ghana, Lesotho, Malawi, South Africa, and Trinidad and Tobago, with a focus on teacher supply. However, such multisite studies tend to research teacher education at each individual site, and then draw inferences based on a synthetic analysis of the multiple, site-based cases. Studies that address interactions between sites are far

\footnotetext{
Article History: Received 17 September $2019 \bullet$ Revised 23 October $2020 \bullet$ Accepted 23 October 2020

(C) 2020 by the authors; licensee Modestum. Open Access terms of the Creative Commons Attribution 4.0 International License (http://creativecommons.org/licenses/by/4.0/) apply. The license permits unrestricted use, distribution, and reproduction in any medium, on the condition that users give exact credit to the original author(s) and the source, provide a link to the Creative Commons license, and indicate if they made any changes.
} 
less common. These studies also tend to focus on systemic processes or standardized measures of student learning, and less on actual pedagogy or specific student learning processes and outcomes.

Studies that address multi-site instructional delivery are not new. For example, Andrews and Klease (1998) examined the use of videotapes, videoconferencing, and collaborative instruction to teach chemistry across the multiple campuses of Central Queensland University in Australia. They found the multi-site model promoted collaboration and improved professional development opportunities for the instructors, while also promoting more interactions amongst students than traditional instructional delivery. However, in the case of teacher education, studies that examine a single program enacted across multiple sites are quite rare.

We begin with a theoretical discussion of multi-site learning, particularly as it applies to teacher education. We make particular distinctions between information delivery models and those that are more interactive (Collins \& Halverson, 2018; Hannafin \& Land, 1997), as the target middle level mathematics endorsement program includes many facets of the latter approach. We draw on the notion of mathematical knowledge for teaching (MKT) (Ball, Thames, \& Phelps, 2008) to frame our discussion of the program goals. MKT involves a connected set of understandings related to mathematical content, teaching, learners, and curriculum.

By setting our research in a cohesive and interactive teacher education model, our results provide insight into specific ways of supporting preservice teacher growth in a multi-site learning environment. Our discussion of the target middle level mathematics endorsement program is given at both systemic and course-specific levels. Our systemic discussion of the program focuses on student-learning goals, instructional philosophy, and delivery method. The five courses that comprise the program content collectively targeted key mathematical content areas and other aspects of MKT. The courses were taught via videoconferencing to four sites. The course-specific aspects of the program are illustrated through descriptions of a variety of contentbased activities and assignments enacted in the individual courses.

A brief report of a study that involved survey and interview data is then provided to illustrate the PSTs' perceptions of their mathematical development. The results indicate growth across all aspects of MKT being measured, including content and pedagogical knowledge. Implications of this work for the improvement of middle level teacher preparation are provided, with a focus on PSTs' development of MKT and the potential for teacher education that stretches across geographic boundaries.

\section{FRAMEWORKS}

\section{Multi-site Educational Models}

As our world becomes more connected internationally, examples of instruction that transcend place are increasingly ubiquitous, particularly at the postsecondary level. Among other forms, distance-based instructional models include large-scale MOOCs, online learning modules, and hybrid courses that combine asynchronous learning with scheduled online or other distance-based interaction. Such instruction is now occurring in many countries, and involve a host of content areas. In short, education is no longer bound by geographic borders, and multi-site educational formats are becoming more the norm.

The distance-learning technologies mentioned above that could support multi-site education are often used to support information delivery models of education. In essence, these technologies replace the traditional large-scale lecture by disseminating information to large numbers of students. However, as our technology advances, the opportunity to enact more community-based, interactive educational formats also grows. For example, Zoom and other videoconferencing technologies allow for meaningful interactions to occur between several individuals or groups of individuals across distances. The nature, processes, and outcomes of multisite education models are dependent on the technological tools at hand. However, the instructional systems and individuals within the system remain the most important factors in defining the educational experience, including the creation of learning experiences that might be labeled interactive or student-centered (Collins \& Halverson, 2018; Hannafin \& Land, 1997; Zhao \& Frank, 2003).

Preservice teacher education, at first glance, might seem froth with pitfalls for multi-site educational approaches. Duke, Francis, and Nagro (2017) claim that preservice teacher education is experiencing a current shift towards distance-based delivery models due to their flexibility and accessibility. However, there is very little data to determine that such models have positive impacts on student dispositions, and mixed results regarding the acquisition of content. Such findings might be due to the intricacies of teacher education and the need to develop key dispositions in PSTs, something that can require long-term and meaningful interactions (Borko, Liston, \& Whitcomb, 2007; Warren, 2018). 
Our study explores the ways in which a multi-site teacher education program delivers instructional content across sites, and how it supports the development of mathematical knowledge for teaching. While the students resided within a single university, implications on the potential for multi-site teacher education, including international models of teacher education, will be explored.

\section{Mathematical Knowledge and Teaching}

While there is a substantial body of evidence on the influence of mathematical knowledge on teaching practices (Ball, Thames, \& Phelps, 2008) and student learning (Kleickmann, Richter, Kunter, Eisner, Besser, Krauss, \& Baumert, 2013), there are only a limited number of studies that explore the influence of teacher education programs on the development of PSTs' mathematical understandings, particularly those important to their instructional development (Grossman, Hammerness, \& McDonald, 2009; Jacob, Hill, \& Corey, 2017; Leavy \& Hourigan, 2016; Senk, Tatto, Reckase, Rowley, Peck, \&Bankov, 2012). A recent review of the literature by Hoover, Mosvold, Ball, and Lai (2016) found that past research tended to focus on effects of teachers' mathematical knowledge on student learning, with only a recent trend toward incorporating teacher education and professional development into these investigations. Hoover et al. (2016) make three important points about the relationship between mathematical knowledge and teaching. First, teacher knowledge of standard disciplinary mathematics is not enough to impact teaching practices. Second, learning mathematics and teaching in integrated ways supports teachers' ability to apply mathematical knowledge in teaching situations. Third, teacher education should maintain a coordination of content and teaching without exclusive focus on one or the other.

There are many frameworks on which to draw when discussing mathematical content knowledge related to teaching. Les Shulman's (1986) use of the term pedagogical content knowledge began an ongoing discussion about the nature of content knowledge important to teachers when engaged in classroom instruction, including the precise nature of the content knowledge that is required to teach effectively. Shulman's contribution was significant in that, for the first time, there was a recognition that teachers' knowledge of content, including mathematics, extended well beyond that commonly learned in classrooms, and that it should be the focus of study by teacher educators (Depaepe, Verschaffel, \& Kelchtermans, 2013). Pedagogical content knowledge in mathematics can include things such as rich, illustrative examples on which to draw when developing mathematical ideas, knowledge of the ways children might think about specific mathematical ideas, and an awareness of how to sequence tasks to support children's development of mathematical ideas.

More recently, the work of Ball et al. (2008) extended Shulman's work with a fine-grained discussion of mathematical knowledge for teaching (MKT). The development of MKT has become a useful theoretical framework when designing professional development experiences for teachers of mathematics. MKT represents a complex web of understandings that involve mathematical content, teaching, learners, and curriculum. There is growing consensus that the development of MKT can lead to an increased awareness and application of instructional practices important in the development of mathematical student learning (Forzani, 2014; McDonald, Kazemi, \& Kavanaugh, 2013). Ball and colleagues have described MKT as a conglomeration of various kinds of knowledge which fall under the categories of subject matter knowledge and pedagogical content knowledge. For the purposes of this paper, we provide detail on the three types of knowledge that comprise MKT that are most closely connected to the general notion of mathematical content knowledge: common content knowledge (CCK), horizon content knowledge (HCK), and specialized content knowledge (SCK).

Ball et al. (2008) describe CCK as "mathematical knowledge we would expect a well-educated adult to know" (p. 395). It is the basic mathematical knowledge we usually learn in school. Second, while there are many perspectives on the nature of HCK (Jakobsen, Thames, Ribeiro, \& Delaney, 2012; Zazkis \& Mamolo, 2011), Ball and Bass (2009) have articulated this aspect of mathematical content knowledge as an awareness of what is ahead and what is behind, "a kind of mathematical 'peripheral vision' needed in teaching, a view of the larger mathematical landscape that teaching requires" (p. 1). HCK provides teachers with a lens that affords connections with mathematical topics normally encountered prior to and after the topic at hand, or to mathematical areas closely related to the topic at hand. The third type of content knowledge, SCK, most closely matches Shulman's original notion of pedagogical content knowledge. It entails the content knowledge unique to teachers and the act of teaching. Hill, Ball, and Schilling (2008) describe this as knowledge that includes "how to accurately represent mathematical ideas, provide mathematical explanations for common rules and procedures, and examine and understand unusual solution methods to problems" (pp. 377-378). Teachers draw 
on SCK when engaging in mathematical conversations with students, such as when seeking to understand student thinking or building on students' mathematical ideas.

Various countries have articulated frameworks for mathematics education through the development of national learning goals or standards that define the intended curriculum. International comparisons, such as the Trends in International Mathematics and Science Study (Hiebert \& colleagues, 2003; Stigler, Gallimore, \& Hiebert, 2000), have surfaced important distinctions in mathematics teaching across international contexts, and studies are beginning to explore the underlying reasons for these differences. For example, Reiss and colleagues (2019) explored relationships between national educational standards, large-scale assessments, and instruction in German-speaking countries, finding direct links across these pieces of the educational systems.

Currently in the U.S., the Common Core State Standards for Mathematics (CCSSM) (National Governors Association, 2010) provide the main organizing structure for mathematics education, including specific learning goals up to age 16. But beyond the articulation of learning standards, the CCSSM also identify eight mathematical practices important to student learning. These practices describe the "varieties of expertise that mathematics educators at all levels should seek to develop in their students" (NGA, 2010, p. 1). Many of these practices draw from perspectives on mathematical knowledge that were articulated previously by the National Council of Teachers of Mathematics (NCTM) and the National Research Council (NRC). In 1989, the NCTM published the landmark Curriculum and Evaluation Standards for School Mathematics (later updated in 2000). This document redefined mathematics to include the process standards of problem solving, reasoning, connections, and communication. Of great significance was that, for the first time, these processes were not just activities performed while doing mathematics, but were considered part of the very essence of mathematics. For example, reasoning should not just be considered as part of the thinking one does when doing mathematics, but instead, reasoning is an actual part of the mathematics under discussion. This shift legitimized the place of these process standards in school curriculum, as well as broadened the focus on the nature of the mathematics being assessed. For example, if students were not problem solving, they were not doing mathematics. If teachers were not assessing their students' abilities to communicate their understandings, they were not adequately assessing their students' mathematical knowledge. The 1989 NCTM Standards document led to significant changes in the nature of mathematics curricula used in U.S. classrooms, such as the inclusion of more genuine problems, the use of multiple representations to develop mathematical ideas, and an increased focus on mathematical connections to contextualized applications (Reys, Reys, Lapan, Holliday, \&Wasman, 2003). However, the impact of this document on the actual teaching of mathematics appeared to be mixed, as while pockets of change were documented, the overall nature of instruction in the U.S. did not appear to change immediately (Jacobs, Hiebert, Givvin, Hollingsworth, Garnier, \& Wearne, 2006; Stigler \& Hiebert, 2009).

Approximately one decade after the groundbreaking NCTM Standards publication, the NRC (2001) publication Adding it $U p$ also articulated a vision of school mathematics for the U.S. This framework described mathematics as five interwoven strands that involve adaptive reasoning, strategic competence, conceptual understanding, productive disposition, and procedural fluency. The use of strategic competence and productive disposition set the stage for several of the CCSSM practices that currently impact K-12 mathematics instruction in the U.S., including the final three practices that involve attending to precision, looking for and making use of structure, and repeated reasoning.

In this paper, we are most interested in the aspects of MKT related to subject matter knowledge. We have chosen to follow closely the NCTM vision of school mathematics in our analysis of PSTs' mathematical knowledge for teaching, as this aligns well with the goals of the target middle level endorsement program and is consistent with key aspects of the subject matter knowledge dimension in the MKT framework. Our data collection is targeted around the four main NCTM process themes mentioned above (reasoning, connections, problem solving, representations), which align with the survey questions used in this study.

\section{INSTRUCTIONAL CONTEXT}

\section{The Middle Level Mathematics Endorsement Program}

The target middle level mathematics endorsement program resides at a large land-grant university in the northwest United States. It is a collaboration between four of the university's campuses and two university departments (Teaching \& Learning and Mathematics). The stated goals of the program are as follows: 
1. Develop a community of learners across campuses that collectively investigate mathematical problems and ideas, and inquire into the teaching of mathematics at the middle school level.

2. Facilitate the development of content knowledge useful for teaching middle level mathematics.

3. Develop understandings of learners, curriculum, and instructional practices related to the teaching of middle level mathematics.

To be accepted into the endorsement, students must have completed or be enrolled in an elementary certification program and have successfully completed a College Algebra course (or equivalent). Most students in the program are prospective teachers enrolled in an undergraduate elementary certification program at one of the four campuses. This means that each site-based group of PSTs enroll simultaneously in the multi-site middle level endorsement program, but each group take all other courses and learning experiences at their own campus locations. The middle level mathematics courses provide the only opportunity for cross-campus collaboration. Besides the PSTs, a small number of students are classroom teachers who desire to improve their ability to teach mathematics.

PSTs obtain the middle level mathematics endorsement through successful completion of five courses: Algebraic Thinking for Middle School Teachers, Geometry for Middle School Teachers, Proportional Reasoning, Teaching Concepts in Probability and Statistics, and Middle Grades Mathematics Methods. The titles suggest that four courses are designed to develop content knowledge and one course focuses on pedagogy. However, while the methods course does foreground pedagogy and the other courses foreground content development, each course provides a blend of both practice-based and content-based learning experiences. The latter is primarily in the form of mathematical problem-solving episodes, performed individually or in groups, that occur both in and out of scheduled class time. The students are usually allowed several minutes to think about and find solutions to a given problem, and then additional time is provided for describing and critiquing the mathematical work shared out. Course instructors model effective instructional practices while facilitating dialogue through the use of core instructional practices such as noticing student thinking, responding to student thinking, and extending on student thinking (Forzani, 2014; McDonald et al., 2013). These instructional moves are intended to advance the mathematical depth and clarity of the discussions, as well as model potentially effective mathematics instructional practices for the PSTs and classroom teachers enrolled in the courses. Practice-related experiences include video- or text-based approximations of practice, empirically-based discussions of how children think mathematically, analysis of children's mathematical work, explorations of mathematical discourse facilitation, and curriculum analysis.

Because of the multi-site nature of the endorsement program, instructional delivery requires significant use of technology and special attention to building a community of learners. The target university has an enhanced videoconferencing system that supports multi-site instruction. Each campus has rooms dedicated to multi-site instruction, with technical staff monitoring cameras and microphones to enhance instructional quality and increase effectiveness. For example, technicians identify and zoom in on student speakers during class discussions and support the use of PowerPoint and document cameras for the presentation of information. There is an approximate one-half second voice time lag across sites, but instructors work with students, particularly in the first days of the course, on proper etiquette and conversational techniques in this environment. In addition, instructors are asked to consider students at other sites as being in their metaphorical front row to ensure they receive as much attention and are allowed as much voice as those students at the same site. Besides the enhanced videoconferencing system, a learning management system (Blackboard) is utilized to support the delivery and collection of materials and assignments, as well as for a variety of communication purposes. Specific mathematical technologies are also used by instructors in each of the courses to support the representation of mathematical ideas and student problem-solving. These include GeoGebra to support geometry instruction, Kuda for statistics and probability, and Desmos for algebra.

\section{Mathematical Tasks and Learning Experiences}

Each of the five courses are taught by university mathematics or mathematics education faculty, doctoral teaching assistants, or K-12 educators with mathematics leadership positions in area schools. Because the establishment of a community of learners is central to a learning environment that enhances student risktaking and communication (Stein, Silver, \& Smith, 1998), particularly in the middle grades (Association for Middle Level Education, 2010; Darling-Hammond \& Bransford, 2005), instructors routinely form student work groups both within and across sites during problem-solving episodes, and as stated above, provide explicit instruction on how to collaborate and communicate across sites. These instructional actions are designed to 


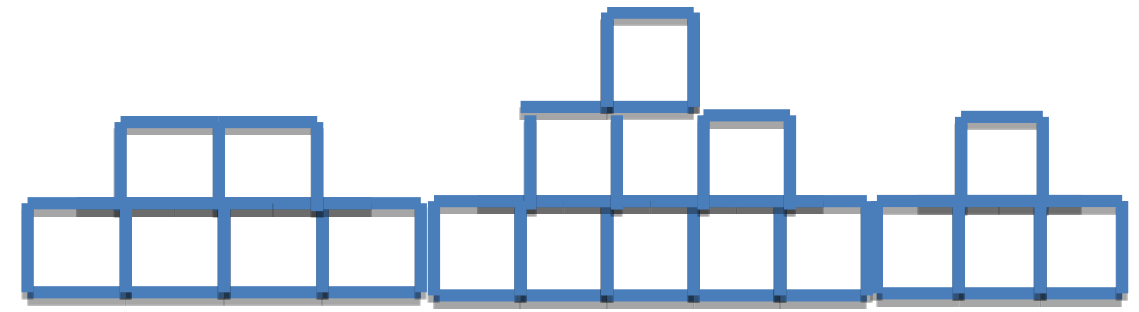

Figure 1. Sample towers provided to the students on the Lego Packing task

support student learning, but also model potentially effective mathematical practices for the PSTs. Cell phones and shared software (e.g., Google docs) help enable this collaborative work across sites. Therefore, a large majority of each class session is devoted to mathematical problem solving and the sharing of solution strategies, with collaborations regularly occurring amongst students at the same and different locations. Instructors make regular use of a think-pair-share approach, with student work displayed via document cameras across the sites to facilitate whole-group discussions.

All classes are scheduled once per week over a 16-week semester for approximately three hours per session, so opportunities for extended mathematical problem-solving sessions are available. Mathematical tasks performed during class time are intended to be challenging, but also able to be performed and discussed within the time constraints of the scheduled class. For example, in the Proportional Reasoning course, students were asked the following question:

A length of string that is $180 \mathrm{~cm}$ long is cut into 3 pieces. The second piece is $25 \%$ longer than the first, and the third piece is $25 \%$ shorter than the first. How long is each piece?

Another problem asked students to compare pairs of fractions (such as 3/5 and 3/7, or 5/8 and 4/6) by relying only on their conceptual understandings of fractions; drawings, materials, or commonly-used procedures were not allowed. In the Algebra course, students were usually asked to work problems that allowed for generalizations of arithmetic or that related to patterns, covariation, and function. For example:

Water is being poured at a constant rate into each vase below. Draw a graph representing the change in the water's height with respect to time for each vase.
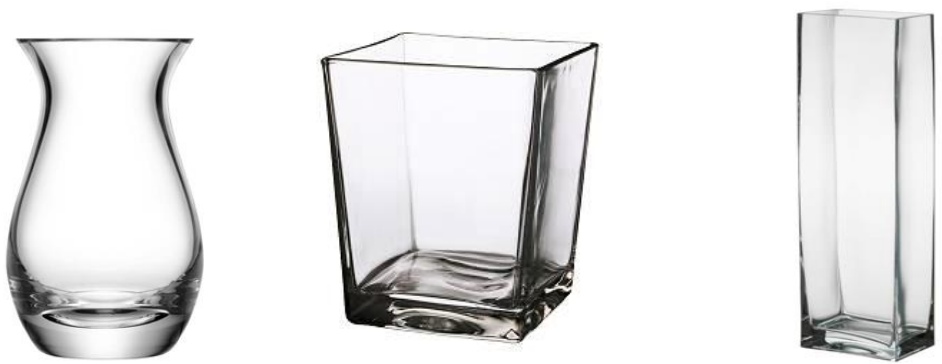

The ability for students to make connections across multiple representations are also encouraged. For example, students were provided unifix cubes and asked to perform the following task:

The Lego packing company is stacking boxes in pyramid shapes. The pyramids can be any height, but at least two rows high (see Figure 1). Also, each row must have two more boxes than the one above it. Is there any total number of boxes that can't be stacked this way? If so, find them.

Some students used unifix cubes to create various towers, while other students drew pictures. The instructor facilitated conversations that focused not only on the answer to the task, but also on justifications for their solutions. For example, one student group claimed the solution was "all prime numbers" and provided the following justification:

We first eliminated all the perfect squares by looking at the first big pyramid we made and realizing that each level produced the perfect square of that row (See Figure 2; Note: The latter comment can be understood by recognizing that, for example, the total number 


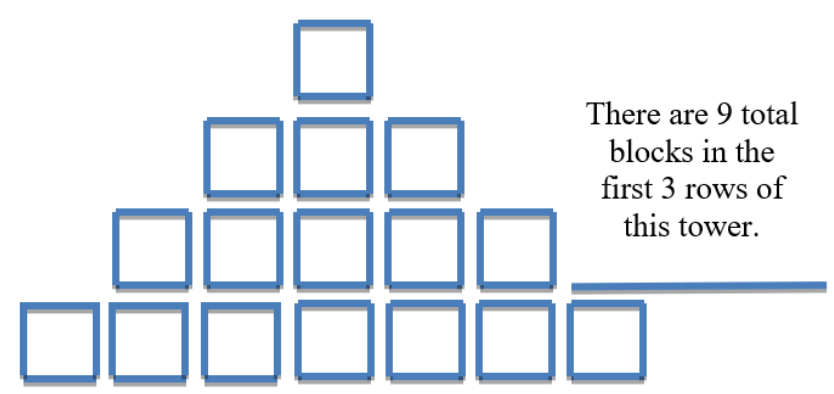

Figure 2. Student illustration of the creation of pyramids with blocks that total to perfect squares on the Lego Packing task

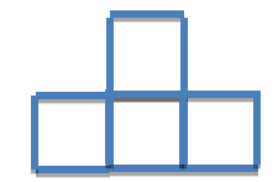

Pyramid of 4 blocks; $2 \times 2$

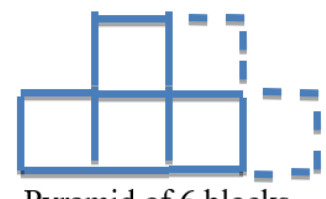

Pyramid of 6 blocks, extending by 2 ; $2 \times 3$

Figure 3. First two cases of the student illustration of the creation of pyramids with blocks that total to multiples of 2 on the Lego Packing task

of blocks in Row 3 and above is 9). So we realized perfect squares work, but we also realized that probably wasn't enough. So we started to look at pyramids of various heights and width. Starting with pyramids of height 2, we quickly saw that we could produce all the multiples of 2 beginning with 2 -squared (Figure 3 ). The same things happened for pyramids of height 3 . We then realized that all the multiples before the perfect square were accounted for by the previous sets of pyramids, so that gave us the multiples of every number. This would only leave the prime numbers as possible ways of not making a pyramid.

As stated above, opportunities to share and discuss the reasoning and strategies embedded in the solutions were provided. While the above argument is not fully-developed, the thinking is quite rigorous and complete, and was understood by most of the other students in the class. The instructor took care in allowing the other students to ask questions and challenge the justification, and highlighted key mathematical and pedagogical features of the solution. For example, the instructor paid specific attention to the invented language of the students (e.g., the relationship between the word "pyramid" and the numbers involved) and the nature of the generalizations made by the students in justifying their cases to all numbers. The instructor furthered this generalization by introducing the following task:

Which natural numbers cannot be written as the sum of two or more consecutive natural numbers?

Students recognized this task as identical to the Lego Packing task, but represented in a very different context. The speed at which this recognition occurred varied greatly, as did the ways in which the connections were noticed. The instructor eventually made explicit the choice of task sequencing and representation, and led a discussion on the pedagogical importance of this planning consideration. Some students commented that this sequence of tasks made them less scared of "ugly math problems" that were decontextualized and written with exclusive use of mathematical terms.

Mathematical tasks are also assigned for completion outside of class time. These assignments are generally more in-depth and extensive, requiring students to delve more deeply into potential mathematical connections and understandings resulting from the assignment. These assignments also provide more opportunities to reflect on course goals related to the development of MKT and make these more explicit and grounded in the experiences of the students. For example, the instructor of the Geometry course introduced the students to various frameworks for mathematical proof and geometric learning throughout the course, including the van Hiele (1985) framework, the SOLO taxonomy (Biggs \& Collis, 1982), and various justification frameworks 
including Stylianides \& Stylianides (2009). A semester-long assignment was created that allowed students to make connections between their own work and the work of their classmates to these frameworks:

You will prepare a final draft of two of the proofs you do this semester. For one of the proofs, please use two of the frameworks to write a 2-3 page self-reflection about your proof. You will swap your second proof with a classmate who will use two of the frameworks to write a 2-3 page observation about your proof, and then you will write a half-page response.

Other assignments were designed to have immediate transfer for use in middle grades classrooms. For example, in the Proportional Reasoning course, the students were required to measure various body lengths and make as many possible connections to the golden ratio as they could find. The instructor provided the following example to help get the students started:

\section{Measure the length $(\mathrm{L})$ of a leg and the distance $(\mathrm{H})$ from the hip to the kneecap. Calculate} and record the ratios $\mathrm{L} / \mathrm{H}$ and $\mathrm{H} /(\mathrm{L}-\mathrm{H})$.

In the algebra course, the instructor provided several pattern generalization tasks, and led class discussions related to the different manners of generalization being modeled as well as others enacted by the students. When focusing on quadratic growth, the following task was given as a homework assignment that extended these in-class learning activities:

A pool measuring 10 meters by 20 meters is surrounded by a path of uniform width (the path borders the entire pool with the same width). If the area of the pool and the path combined is 600 square meters, find the width of the path using two different methods. Examples of methods: Factor, quadratic formula, complete the square, algebra tile drawings, etc.

\section{METHODOLOGY}

The previous section described the multi-site teacher education program that is the context of this study. We now offer a brief report that addresses the following research question: To what degree does a multi-site middle level mathematics endorsement program support prospective teachers' development of mathematical understandings?

Our case study methodology (Merriam, 1998) draws on both quantitative and qualitative data. We agree with Merriam (1998) that a case is a bounded system which allows for the investigation of a specific phenomenon. In our case, the system is the multi-site, middle level preservice mathematics endorsement program, and the phenomenon of focus is the development of MKT. The use of a case study allows us to investigate our phenomenon of focus in this bounded environment. However, because we pay particular focus to the interactive and multi-site nature of the endorsement program, our findings related to preservice teacher development of MKT both broadens our collective understanding of this phenomenon and offers potential implications on similar settings (Merriam, 1998).

The data corpus consists of a combination of quantitative and qualitative data. Survey data involved three collection points over a one-year period and involved a series of Likert-scale items related to multiple facets of MKT, and one open-ended item. Two student focus group interviews were conducted at the conclusion of the survey data collection in order to confirm, disconfirm, or expand on results from the survey analysis.

\section{Participants}

All students enrolled in the middle level mathematics endorsement program during the Fall 2016, Summer 2017, and Fall 2017 semesters were invited to participate in the study. All but two of these students were enrolled simultaneously in an undergraduate elementary certification program, taking the five endorsement classes in addition to the elementary certification coursework over a two-year period. Two students were enrolled in a graduate-level education program. All students had successfully completed a mathematics course equivalent to College Algebra or higher.

Survey responses from the Fall 2016, Summer 2017, and Fall 2017 semesters were analyzed. Approximately 50 different students were asked to complete the survey, with many of these responding more than once over the course of the study. A total of 91 responses were received across the three surveys. These 


\begin{tabular}{|c|c|c|}
\hline Semester Term & Recommended Course & \\
\hline Summer before Year 3 & Teaching Concepts of Probability and Statistics & \\
\hline Fall of Year 3 & Proportional Reasoning & \\
\hline Spring of Year 3 & Algebraic Thinking for the Middle School Teacher & \\
\hline Summer before Year 4 & Geometry for the Middle School Teacher & \\
\hline Fall of Year 4 & Middle Level Mathematics Methods & \\
\hline Spring of Year 4 & Student Teaching & \\
\hline
\end{tabular}

Figure 4. The suggested pathway through the middle level mathematics endorsement for an undergraduate elementary certification student

1. The program has increased my content knowledge of middle level mathematics.

2. The program has improved my ability to solve mathematical problems.

3. The program has improved my ability to justify my reasoning mathematically.

4. The program has increased my understanding of the connections between mathematical concepts.

5. The program has improved my fluency with multiple representations in mathematics.

Figure 5. Five Likert-scale survey items designed to measure prospective teachers' self-perceptions of their own mathematical learning

data collection points were targeted to allow for survey analysis at three points in time, and to also afford an analysis of change over time for one student group. Specifically, students who had completed one or two endorsement courses in Fall 2016 were identified, as well as students who had completed three, four, or five courses in Fall 2017. Because of the typical path to completion for this cohort of students (Figure 4), the students in each of these two groups were nearly identical, allowing for a comprehensive view of change over time for this cohort.

Though the program was offered via videoconferencing to four different sites, approximately half of the students in each course were at one of two sites, with little to no enrollment at the other two sites; the largest number of students at one of the smaller-enrolled sites for any of the three surveys was five. The course instructor was physically present at one of the larger-enrolled sites for all five of the courses that span this study. The second author was the instructor for two of these courses, and the first author was the endorsement program coordinator.

\section{Data Collection}

\section{Survey}

Five items from a larger survey (Slavit, deVincenzi, Akmal, \& Lesseig, 2018) were used as a primary data source (Figure 5). These items addressed specific aspects of MKT related to problem solving, justification, connections, and representations, as well as a general item on content knowledge of middle level mathematics (Figure 5). One open-ended survey item yielded additional information on the students' self-perceptions of their MKT.

\section{Focus group interviews}

Two student focus group interviews were conducted in Fall 2016 to provide more fine-grained analysis of the students' self-perceptions of their MKT status and growth. The focus group interviews were conducted shortly after the survey and were transcribed. A total of eight questions were asked that focused on a variety of program aspects; two particular questions were analyzed most fully for this particular study:

1. What are some things that you have learned in this program that you think are essential for all middle level math teachers to know or be able to do?

2. Do you feel the program is preparing you to teach mathematics at the middle school level? (Probe on content knowledge - problem solving, justification of reasoning, connections between concepts, and representations) Why and/or why not?

\section{Data Analysis}

Means were calculated on the responses for all items on all surveys, as well as each individual survey, to provide information on the influence of the program on the PSTs' development of the various aspects of MKT under consideration. The survey was given anonymously with no personal identifier in order to encourage 
Table 1. Mean across three surveys on the five items related to preservice teachers' mathematical content knowledge, subdivided by students who took 1-2 courses and those who took 3-5 courses

\begin{tabular}{|c|c|c|c|c|c|c|c|c|}
\hline & & $\begin{array}{l}\text { Students } \\
\text { Enrolled }\end{array}$ & $\begin{array}{l}\text { Students } \\
\text { Surveyed }\end{array}$ & $\begin{array}{l}\text { General } \\
\text { Content }\end{array}$ & $\begin{array}{c}\text { Problem } \\
\text { Solving }\end{array}$ & Justification & Connections & Representation \\
\hline $\begin{array}{l}\text { Fall } \\
2016 \\
\end{array}$ & $\begin{array}{c}1-2 \\
\text { Courses }\end{array}$ & & 13 & 3.27 & 3.47 & 3.27 & 3.53 & 3.47 \\
\hline & $\begin{array}{c}3-5 \\
\text { Courses } \\
\end{array}$ & & 15 & 4.20 & 4.20 & 4.27 & 4.33 & 4.47 \\
\hline & All & 35 & 28 & 4.00 & 4.11 & 4.04 & 4.21 & 4.25 \\
\hline $\begin{array}{l}\text { Sum } \\
2017\end{array}$ & $\begin{array}{c}1-2 \\
\text { Courses }\end{array}$ & & 3 & 5.00 & 4.67 & 4.67 & 4.67 & 4.67 \\
\hline & $\begin{array}{c}3-5 \\
\text { Courses } \\
\end{array}$ & & 14 & 4.07 & 4.00 & 4.14 & 3.71 & 4.00 \\
\hline & All & 17 & 17 & 4.24 & 4.12 & 4.24 & 3.88 & 4.12 \\
\hline $\begin{array}{l}\text { Fall } \\
2017\end{array}$ & $\begin{array}{c}1-2 \\
\text { Courses } \\
\end{array}$ & & 11 & 4.55 & 4.45 & 4.45 & 4.45 & 4.55 \\
\hline & $\begin{array}{c}3-5 \\
\text { Courses }\end{array}$ & & 13 & 4.31 & 4.08 & 4.23 & 4.15 & 4.31 \\
\hline & All & 39 & 24 & 4.42 & 4.25 & 4.33 & 4.29 & 4.42 \\
\hline Total & $\begin{array}{c}1-2 \\
\text { Courses } \\
\end{array}$ & & 27 & 4.22 & 4.26 & 4.15 & 4.30 & 4.30 \\
\hline & $\begin{array}{c}3-5 \\
\text { Courses } \\
\end{array}$ & & 42 & 4.05 & 4.03 & 4.05 & 3.98 & 4.10 \\
\hline & All & 91 & 69 & 4.20 & 4.16 & 4.09 & 4.16 & 4.28 \\
\hline
\end{tabular}

accurate and trustworthy student responses, although this prevented match-paired analyses of the survey data. However, as stated above, matched groups were identified in Fall 2016 and Fall 2017 through the identifying information of number of courses taken. This allowed for analyses of student progress over time through simple comparisons of percentage difference.

The open-ended survey item was coded qualitatively after the quantitative analysis to provide confirmation, differences, or new directions with respect to the quantitative findings. Responses to the openended item and interview responses were analyzed by both authors individually, and then collectively. Initial themes related to the PSTs' development of MKT were shared. The authors then collectively analyzed both the responses to the open-ended item and the transcripts of the focus group interviews to verify themes, refine themes, and identify new themes (Saldaña, 2015). The eventual themes corresponded to the five areas of MKT previously articulated, with sub-themes that included procedural or conceptual orientation, application to teaching, incorporation of student thinking, and learning through one's own problem solving.

\section{RESULTS}

Table 1 provides mean responses for each item related to the PSTs' self-perception of the five aspects of MKT addressed on all three surveys (Figure 5), as well as overall means across all three survey responses combined. No meaningful differences can be found in the overall results across the five areas of MKT under consideration, with each area in the 4.0 and 4.3 range, indicating that the MKTs' self-perception of their learning was quite high. Overall, students who had taken just 1-2 courses rated their own learning higher than those who had taken 3-5 courses. While this pattern was also found in the Fall 2016 survey, the trend was not repeated in Fall 2017, for which the 1-2 course students indicated higher degrees of learning than the 3-5 course students. However, the latter was due to the exceptionally high responses provided by the 1-2 course students on that survey. The limited number of responses from 1-2 course students in the Summer 2017 survey does not allow for any meaningful comparison.

An analysis of the responses from the 1-2 course students in Fall 2016 and the 3-5 course students in Fall 2017 provides direct evidence on the impact of the program on a stable population of students. Gains were made on each mathematical area under consideration, including an increase in general content knowledge by .78 (24\% increase), problem solving by .56 (16\% increase), justification by .78 (24\% increase), connections by $.45(13 \%)$, and representations by .63 (18\%).

Comments from the open-ended survey item and student interview confirmed these findings, with consistent mention of the program's impact on the PSTs' mathematical knowledge throughout the study. Many 
of these comments targeted specific areas of MKT, such as the following comment related to the importance of mathematical representations:

The idea of multiple representations is the most essential component of middle school mathematics. Students need to be able to represent their thinking in a variety of ways. Therefore, middle school math teachers need to be flexible and understanding because each student learns differently.

PST comments also connected their perceived growth to specific program learning experiences. One PST stated:

\begin{abstract}
She (our instructor) taught us all about problem solving, reasoning, and connections between concepts. She didn't just lecture about these; she had us explore them in depth. We got to complete hands-on activities that we can use with our students in the future. In regard to productive struggle, mathematical discourse, student responses, and reasoning, we've completed assignments that demonstrate mastery of each. I feel much more confident in my decision to become a math teacher.
\end{abstract}

\title{
CONCLUSIONS
}

There is limited evidence on the relationships betwen middle level mathematics endorsement programs and PSTs' development of MKT. Cardetti and Truxaw (2014) found positive results in the context of specific middle level mathematics endorsement courses designed for this purpose, and others have found increases for specific pedagogical aspects of MKT, such as orchestrating discussions (Morris, Hiebert, \& Spitzer, 2009; Spangler \& Hallman-Thrasher, 2014). The survey results, confirmed by the PST comments, show that positive impacts on the development of MKT, including specific aspects of MKT, can be obtained in a multi-site learning environment (Andrews \& Klease, 1998; Duke et al., 2017), in this case a middle level mathematics endorsement program. Evidence from the target PST population documents increases in all areas of MKT over their time in the endorsement program. Curricular and instructional efforts to target specific aspects of MKT were important in this effort, a finding similar to Morris, Hiebert, and Spitzer (2009), who found increases in PSTs' MKT in the context of lesson planning and student work analysis. In our context, intentional instructional moves to build community within and across the sites and engage the PSTs in active learning experiences that targeted both MKT and the corresponding ability to teaching middle level mathematics were also important.

The program courses targeted the development of specific aspects of MKT, and instructors were supported in finding learning experiences that would lead to this development. The latter included in-class activities that encouraged PSTs' problem solving, but also follow-up conversations that deconstructed the pedagogic design of these experiences in regard to things such as task sequencing, choice of representation(s), conceptual and procedural emphasis, and level of cognitive challenge. The PSTs were in a position to continuously reflect on their own mathematical thinking, the mathematical thinking of others (including both their fellow PSTs and the work of middle level mathematics students provided by the instructors), and the decision-making of their instructors that led to these reflections. This proved to be an effective mix of experiences in promoting the growth of MKT amongst the PSTs in this middle level mathematics endorsement program (Cardetti \& Truxaw, 2014).

Limitations of this study reduce the ability to generalize these findings beyond the given context. While the teacher education program was multi-site in nature, the fact that all students were from the same university and in the same geographic area of the U.S. limits the opportunity for direct comparisons to other multi-site settings, including in broader geographic areas or in international contexts. The teacher education program also targeted a very specific PST learning outcome, namely MKT, which limits the ability to make comparisons to broader teacher education program goals. The nature of the survey and focus group interviews is self-reported by the PSTs, decreasing its reliability.

\section{IMPLICATIONS}

The first implication of this study is that university-based experiences can positively impact the development of MKT in prospective teachers. This link between teacher education and PST learning is important, as this capacity-building aspect of teacher education should not be assumed (Hoover et al., 2016; 
Senk et al., 2012). Because of the importance of middle level mathematics on the development and attitudes of students (Association for Middle Level Education, 2010; Wang \& Goldschmidt, 2003), which influences career choice (Sadler, Sonnert, Hazari, \& Tai, 2012; Maltese, Meiki, \&Wiebke, 2014), supporting PSTs in this endeavor is critical. The evidence in this study shows the possibility of a middle level mathematics endorsement program's ability to influence PST development.

The second implication of this study is that this link between instruction and learning occurred in a multisite teacher education program. While the various groups of students were at the same university, they were only connected across sites by the videoconferencing and other distance learning tools that defined their course experiences. Beyond these learning experiences, the different groups of PSTs were located physically at different sites, experienced an entirely different set of instructors and instructional norms in their other teacher education courses, and participated in school-based field experiences that were enacted in different geographic contexts. We hypothesize that our model of multi-site teacher education, which is focused on a very specific teacher education goal (in this case, the development of MKT), can be extended across other geographic contexts.

This hypothesis is based in part on the efforts, and eventual successes, of the program to build a unique community of learners, which afforded an environment that promoted collaboration and learning. This involved carefully designed and implemented approaches to community building within and across the sites, a process found to be important in other studies of multi-site instruction (Andrews \& Klease, 1998; Duke et al., 2017). Not only did these efforts model sound pedagogical practices, but they supported the PSTs in communicating their mathematical ideas and justifications, as well as their thoughts on the implications of their learning experiences on their future teaching practices. The establishment of a community of learners supported the additional programmatic efforts to focus on key aspects of MKT through the use of active, conceptually-based mathematical learning experiences. All teacher education programs, including those that focus on middle level mathematics, should consider in their design the building of a community of learners as a central support to student learning.

Can multi-site teacher education programs exist effectively across national borders? Our case involved a multi-site university, which can perhaps support the establishment of a learning community as it resides in the same educational system and has somewhat similar, local educational contexts across the sites. When considering multi-site teacher education across regions of a country, or even in international contexts, these challenges become significant or even prohibitive; teacher education across international contexts has a multitude of barriers to consider. These could include language differences, inconsistencies across national educational goals and norms, and a variety of systematic differences at both the K-12 and postsecondary levels that involve curriculum, instruction, and assessment (Jacobs et al., 2006; Reiss et al., 2019).

We are making no claim that the establishment of teacher education programs across multiple international sites would be easy. Our study only provides evidence that multi-site teacher education can be effective within a single geographic region and within a specific teacher education focus (in this case, middle level mathematics).However, if technology that affords community building is present, avenues of communication open up that might provide opportunities for teacher education to take on new forms. For example, if a content-based pedagogy course were instructed across international sites, opportunities to share national, regional, and local instructional norms would present themselves in a very natural way. Curriculum, teacher collaboration, large-scale and formative assessment, and a whole host of other pedagogical issues could be compared across the sites, providing opportunities for reflection on current norms as well as insights into other ways of teaching. If accompanied by proper technological supports, and if enacted in a manner that supports the development of community across sites, we wonder about the precise limits to the geographic scope of teacher education.

\section{Disclosure statement}

No potential conflict of interest was reported by the authors.

\section{Notes on contributors}

David Slavit - Washington State University Vancouver, USA.

Allison Therese deVincenzi - Washington State University Vancouver, USA. 


\section{REFERENCES}

Abell, S. K., Lannin, J. K., Marra, R. M., Ehlert, M. W., Cole, J. S., Lee, M. H., Park Roger, M. A., \& Wang, C. Y. (2007). Multi-site evaluation of science and mathematics teacher professional development programs: The project profile approach. Studies in Educational Evaluation, 33(2), 135-158. https://doi.org/10.1016/j.stueduc.2007.04.003

Andrews, T., \& Klease, G. (1998). Challenges of multisite video conferencing: The development of an alternative teaching/learning model. Australasian Journal of Educational Technology, 14(2), 88-97. https://doi.org/10.14742/ajet.1902

Association for Middle Level Education. (2010). This we believe: Keys to educating young adolescents. Westerville, OH: National Middle School Association.

Ball, D. L., \& Bass, H. (2009). With an eye on the mathematical horizon: Knowing mathematics for teaching to learners' mathematical futures. Paper presented at the 43rd JahrestagungfürDidaktik der Mathematik. Retrieved from http://www.mathematik.tudortmund.de/ieem/cms/media/BzMU/BzMU2009/Beitraege/ Hauptvortraege/BALL_Deborah_BASS_Hyman_2009_Horizon.pdf

Ball, D. L., Thames, M. H., \& Phelps, G. (2008). Content knowledge for teaching: What makes it special? Journal of Teacher Education, 59(5), 389-407. https://doi.org/10.1177/0022487108324554

Biggs, J. B., \& Collis, K. F. (1982). Evaluating the quality of learning: The SOLO Taxonomy (Structure of the Observed Learning Outcome). New York: Academic Press.

Borko, H., Liston, D., \& Whitcomb, J. A. (2007). Apples and fishes: The debate over dispositions in teacher education. Journal of Teacher Education, 58(5), 359-364. https://doi.org/10.1177/0022487107309977

Cardetti, F., \& Truxaw, M. P. (2014). Toward improving the mathematics preparation of elementary preservice teachers. School Science and Mathematics, 114(1), 1-9. https://doi.org/10.1111/ssm.12047

Collins, A., \& Halverson, R. (2018). Rethinking education in the age of technology: The digital revolution and schooling in America. New York: Teachers College Press.

Darling-Hammond, L., \& Bransford, J. (2005). Preparing teachers for a changing world: What teachers should learn and be able to do. San Francisco, CA: Jossey-Bass.

Depaepe, F., Verschaffel, L., \& Kelchtermans, G. (2013). Pedagogical content knowledge: A systematic review of the way in which the concept has pervaded mathematics educational research. Teaching and Teacher Education, 34, 12-25. https://doi.org/10.1016/j.tate.2013.03.001

Duke, J., Francis, G., \&Nagro, S. (2017). Student engagement across distance learning models. In Innovations in Teaching \& Learning Conference Proceedings (Vol. 9). Fairfax, VA: Mason Publishing. Retrieved from https://journals.gmu.edu/ITLCP/article/view/1849/0

Forzani, F. M. (2014). Understanding "core practices" and "practice-based" teacher education: Learning from the past. Journal of Teacher Education, 65(4), 357-368. https://doi.org/10.1177/0022487114533800

Grossman, P., Hammerness, K., \& McDonald, M. (2009). Redefining teaching, re-imagining teacher education. Teachers and Teaching: Theory and Practice, 15(2), 273-289. https://doi.org/10.1080/13540600902875340

Hannafin, M. J., \& Land, S. M. (1997). The foundations and assumptions of technology-enhanced studentcentered learning environments. Instructional Science, 25(3), 167-202. https://doi.org/10.1023/A:1002997414652

Hiebert, J., Gallimore, R., Garnier, H., Givvin, K. B., Hollingsworth, H., Jacobs, J., \& Stigler, J. (2003). Teaching mathematics in seven countries: Results from the TIMSS 1999 video study. Education Statistics Quarterly, 5(1), 7-15. https://doi.org/10.1037/e610352011-003

Hill, H. C., Ball, D. L., \& Schilling, S. G. (2008). Unpacking pedagogical content knowledge: Conceptualizing and measuring teachers' topic-specific knowledge of students. Journal for Research in Mathematics Education 39(4), 372-400.

Hoover, M., Mosvold, R., Ball, D. L., \& Lai, Y. (2016). Making progress on mathematical knowledge for teaching. The Mathematics Enthusiast, 13(1), 3-34.

Jacob, R., Hill, H., \& Corey, D. (2017). The impact of a professional development program on teachers' mathematical knowledge for teaching, instruction, and student achievement. Journal of Research on Educational Effectiveness, 10(2), 379-407. https://doi.org/10.1080/19345747.2016.1273411 
Jacobs, J., Hiebert, J., Givvin, K., Hollingsworth, H., Garnier, H., \& Wearne, D. (2006). Does eighth-grade mathematics teaching in the United States align with the NCTM Standards? Results from the TIMSS 1995 and 1999 video studies. Journal for Research in Mathematics Education, 37(1), 5-32. https://doi.org/10.2307/27646307

Jakobsen, A., Thames, M. H., Ribeiro, C. M., \& Delaney, S. (2012). Using practice to define and distinguish horizon content knowledge. In S. J. Cho (Ed.), 12th International Congress in Mathematics Education (12th ICME) (pp. 4635-4644). New York: Springer.

Kleickmann, T., Richter, D., Kunter, M., Elsner, J., Besser, M., Krauss, S., \& Baumert, J. (2013). Teachers' content knowledge and pedagogical content knowledge: The role of structural differences in teacher education. Journal of Teacher Education, 64(1), 90-106. https://doi.org/10.1177/0022487112460398

Leavy, A. M., \& Hourigan, M. (2016). Using lesson study to support knowledge development in initial teacher education: Insights from early number classrooms. Teaching and Teacher Education, 57, 161-175. https://doi.org/10.1016/j.tate.2016.04.002

Lewin, K. M. \& Stuart, J. S. (2003). Researching teacher education: New perspectives on practice, performance and policy. Multi-Site Teacher Education Research Project (MUSTER) synthesis report (Education Research Paper, No. 49a). London, Department for International Development.

Maltese, A. V., Melki, C. S., \& Wiebke, H. L. (2014). The nature of experiences responsible for the generation and maintenance of interest in STEM. Science Education, 98(6), 937-962. https://doi.org/10.1002/sce.21132

McDonald, M., Kazemi, E., \& Kavanagh, S. S. (2013). Core practices and pedagogies of teacher education: A call for a common language and collective activity. Journal of Teacher Education, 64(5), 378-386. https://doi.org/10.1177/0022487113493807

Merriam, S. B. (1998). Qualitative research and case study applications in education. San Francisco: JosseyBass Inc.

Morris, A. K., Hiebert, J., \& Spitzer, S. M. (2009). Mathematical knowledge for teaching in planning and evaluating instruction: What can preservice teachers learn? Journal for Research in Mathematics Education, 40(5), 491-529. https://doi.org/10.5951/jresematheduc.40.5.0491

National Council of Teachers of Mathematics (NCTM) (1989). Curriculum and evaluation standards for school mathematics. Reston, VA: Author.

National Council of Teachers of Mathematics (NCTM) (2000). Principles and standards for school mathematics. Reston, VA: Author.

National Governors Association (NGA) (2010). Common core state standards for mathematics. Washington D.C: Author.

National Research Council (NRC), \& Mathematics Learning Study Committee. (2001). Adding it up: Helping children learn mathematics. Washington, D.C.: National Academies Press.

Reiss, K., Obersteiner, A., Heinze, A., Itzlinger-Bruneforth, U., \& Lin, F. L. (2019). Large-scale studies in mathematics education research. In H. N. Jahnke \& L. Hefendehl-Hebeker (Eds.), Traditions in German-Speaking Mathematics Education Research (pp. 249-278). New York: Springer. https://doi.org/10.1007/978-3-030-11069-7_10

Reys, R., Reys, B., Lapan, R., Holliday, G., \&Wasman, D. (2003). Assessing the impact of "standards"-based middle grades mathematics curriculum materials on student achievement. Journal for Research in Mathematics Education, 34(1), 74-95. https://doi.org/10.2307/30034700

Sadler, P. M., Sonnert, G., Hazari, Z., \& Tai, R. (2012). Stability and volatility of STEM career interest in high school: A gender study. Science Education, 96(3), 411-427. https://doi.org/10.1002/sce.21007

Saldaña, J. (2015). The coding manual for qualitative researchers. New York: Sage.

Senk, S. L., Tatto, M. T., Reckase, M., Rowley, G., Peck, R., \& Bankov, K. (2012). Knowledge of future primary teachers for teaching mathematics: An international comparative study. ZDM Mathematics Education, 44(3), 307-324. https://doi.org/10.1007/s11858-012-0400-7

Shulman, L. S. (1986). Those who understand: Knowledge growth in teaching. Educational Researcher, 15(2), 4-14. https://doi.org/10.3102/0013189X015002004 
Slavit, D., deVincenzi, A., Akmal, T., \& Lesseig, K. (2018). Promoting community and core practices in a multisite middle level mathematics program. In P. B. Howell, S. A. Faulkner, J. Jones, \& J. Carpenter (Eds.), Preparing middle level educators for 21st century schools: Enduring beliefs, changing times, evolving practices (pp.179-202). Charlotte, NC: Information Age.

Spangler, D. A., \& Hallman-Thrasher, A. (2014). Using task dialogues to enhance preservice teachers' abilities to orchestrate discourse. Mathematics Teacher Educator, 3(1), 58-75. https://doi.org/10.5951/mathteaceduc.3.1.0058

Stein, M. K., Silver, E. A., \& Smith, M. S. (1998). Mathematics reform and teacher development: A community of practice perspective. Thinking practices in mathematics and science learning, 14(1), 21-32.

Stigler, J. W., \& Hiebert, J. (2009). The teaching gap: Best ideas from the world's teachers for improving education in the classroom. New York: Simon and Schuster.

Stigler, J. W., Gallimore, R., \& Hiebert, J. (2000). Using video surveys to compare classrooms and teaching across cultures: Examples and lessons from the TIMSS video studies. Educational Psychologist, 35(2), 87-100. https://doi.org/10.1207/S15326985EP3502_3

Stylianides, G. J., \& Stylianides, A. J. (2009). Facilitating the transition from empirical arguments to proof. Journal for Research in Mathematics Education, 40(3), 314-352.

van Hiele, P. M. (1985). The child's thought and geometry. In D. Fuys, D. Geddes, \& R. Tischler (Eds.), English translation of selected writings of Dina van Hiele-Geldof and Pierre M. van Hiele (pp. 243-252). Brooklyn, NY: Brooklyn College, School of Education. (Original work published 1959)

Wang, J., and Goldschmidt, P. (2003). Importance of middle school mathematics on high school students' mathematics achievement. The Journal of Educational Research, 97(1), 3-19. https://doi.org/10.1080/00220670309596624

Warren, C. A. (2018). Empathy, teacher dispositions, and preparation for culturally responsive pedagogy. Journal of Teacher Education, 69(2), 169-183. https://doi.org/10.1177/0022487117712487

Zazkis, R., \& Mamolo, A. (2011). Reconceptualizing knowledge at the mathematical horizon. For the Learning of Mathematics, 31(2), 8-13.

Zeichner, K., \& Conklin, H. G. (2008). Teacher education programs as sites for teacher preparation. In M. Cochran-Smith, S. Feiman-Nemser, D. J. McIntyre, \& K. E. Demers (Eds.), Handbook of research on teacher education: Enduring questions in changing contexts (pp. 269-289). New York: Routledge.

Zhao, Y., \& Frank, K. A. (2003). Factors affecting technology uses in schools: An ecological perspective. American Educational Research Journal, 40(4), 807-840. https://doi.org/10.3102/00028312040004807 